\author{
BRAZILIAN JOURNAL \\ $\mathrm{OF}$ \\ RADIATION SCIENCES \\ 07-2A (2019) 01-09
}

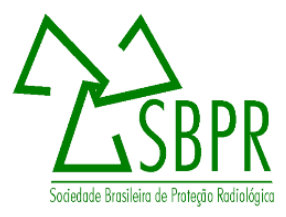

\title{
GALLIUM-67 CITRATE USED AS A TRACER OF ACETONE PRODUCTION ROUTES
}

\author{
C. H. de Mesquita, W. A. P. Calvo, P. E. Aoki, V. C. da Silva, M. I. Haraguchi, A. F. \\ Velo, A. G. Alvarez and M. M. Hamada \\ Instituto de Pesquisas Energéticas e Nucleares- IPEN/CNEN-SP. 05508-000, São Paulo, São Paulo, Brasil \\ chmesqui@gmail.com
}

\begin{abstract}
In this work the pathway of the chemical product and the kinetics parameters were evaluated in a laboratory plant settled, using $0.4 \mathrm{GBq}(10 \mathrm{~mL})$ of ${ }^{67} \mathrm{Ga}$ citrate as radiotracer and $18 \mathrm{NaI}(\mathrm{Tl})$ radiation detectors. The AnaComp program was used to estimate the kinetic para ameters of the acetone production. The yield of the acetone production was estimated by the percentage ratio between the areas under the curve (AUC) of the curve profiles of the final product compartment divided by the concentration found inside the chemical reactor whose result was $87 \%$ yield during the first 30 minutes of reaction.
\end{abstract}

Keywords: Quality Evaluation; Compartmental analysis; Galium-67 radiotracer. 


\section{INTRODUCTION}

Acetone is widely used in hospitals, laboratories, cosmetics and chemical industries. In addition, it is also widely used as a solvent in several applications, such as for extraction of fats and oils in the pharmaceutical industry [1]. Commercially, acetone is most used in the production of methyl methacrylate [MMA], methyl isobutyl ketone [MIBK] and bisphenol A [BPA] [2] in the chemical industries. In 2010, the worldwide production capacity for acetone was estimated at 6.7 million tons per year and the expectative is an increase of approximately $4 \%$ per year in its demand $[2,3]$.

The main production methods of acetone are: oxidation of cumene, oxidation of propylene, oxidation of diisopropyl benzene, fermentation of biomass and dehydrogenation of isopropyl alcohol [4]. The cumene oxidation is now the most commonly used technology, approximately $90 \%$ of the world production, since it presents lower costs in relation to the other methods [3].

The radiotracer techniques for industrial processes evaluation have been indicated as the most promising in order to evaluate the kinetic properties along all process. It is capable to obtain measurements in real conditions without interrupting the operation and non-invasive sampling. The radiotracer techniques are widely used in many industries, such as: chemical, food pharmaceutical and oil sectors, in order to diagnose and identify failure in their industrial process [5].

The AnaComp program (Compartmental Analysis) [6] is a computational code designed for the analysis of kinetic data in terms of models. It allows the simulation and the fitting of experimental data using an iconographic language that translates to the symbology of the compartmental analysis [6]. In this work the pathway of the chemical product and the kinetics parameters were evaluated in a laboratory plant settled in our Radiation Technology Centre, using $0.4 \mathrm{GBq}(10 \mathrm{~mL})$ of ${ }^{67} \mathrm{Ga}$ citrate as radiotracer and $18 \mathrm{NaI}(\mathrm{Tl})$ radiation detectors. The AnaComp code [6] was used to estimate the kinetic parameters of the acetone production. 


\section{MATERIALS AND METHODS}

In order to study the pathway of the chemical product and the kinetics parameters of the chemical process, it was used $18 \mathrm{NaI}(\mathrm{Tl})$ of $25 \mathrm{~mm}$ diameter and $50 \mathrm{~mm}$ thick distributed as shown in Fig. 1.

Figure 1: Scheme of the experimental process and the compartmental model.

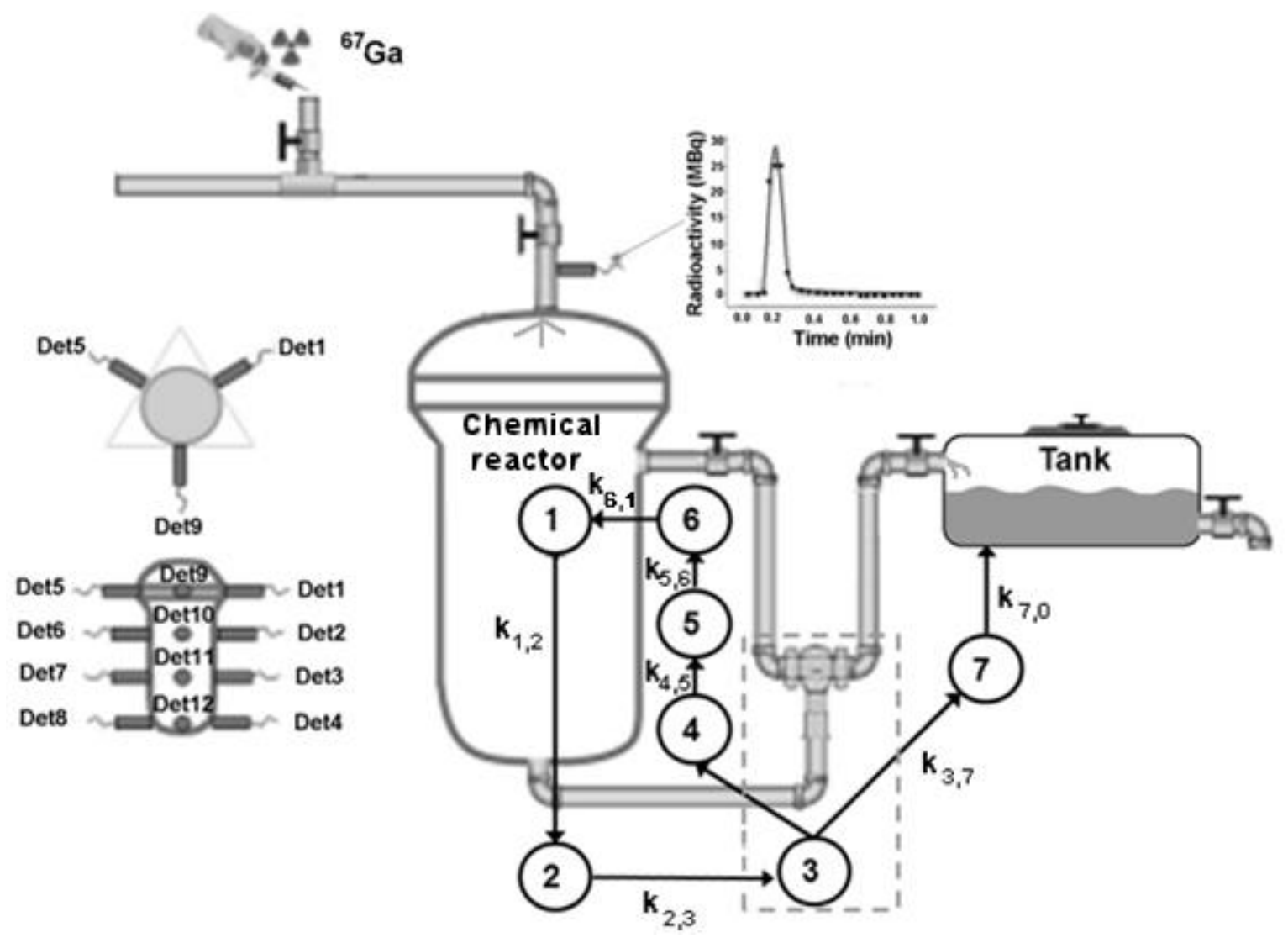

Detector and multichannel board is shown in Fig. 2. $0.4 \mathrm{GBq}$ of ${ }^{67} \mathrm{Ga}$ citrate was used as radiotracer. This was injected into the entrance of the chemical reactor by means of a hypodermic syringe wrapped with lead for radioprotection purposes. Immediately after adding radiotracer into the system, radioactivity measurements were started on all 18 detectors, simultaneously. The count time was performed at $33 \mathrm{~ms}$ in sequential mode. The kinetic parameters, the fraction $\mathrm{k}_{\mathrm{i}, \mathrm{j}}\left(\mathrm{min}^{-1}\right)$ of the contents of 
the compartment $\boldsymbol{i}$ which is transferred to the compartment $\boldsymbol{j}$ in one unit of time, the residence time, equation (1), the mean time $\mathrm{T}_{1 / 2}$, equation (2), the arrival time of the radiotracer in each of the compartments assumed to be the time that the maximum value of the compartment kinetic curve occurred. All these parameters were estimated using the AnaComp code [6]. The residence time of the tracer in each of the compartments was calculated according to equation (1) and the mean residence time was estimated by equation (2).

$$
\begin{gathered}
\text { Residence Time }=\frac{1}{k_{i, j}} \\
\text { Mean Time }=\frac{\log _{e}(2)}{k_{i, j}} \cong \frac{0.693}{k_{i, j}}
\end{gathered}
$$

The radioactivity measurement system is shown in Fig. 2. It is constituted of $14 \mathrm{NaI}(\mathrm{Tl})$ scintillator detectors connected to a multichannel analyzer [7]. The measurements were carried out in the window range of 50 to $350 \mathrm{keV}$ calibration of ${ }^{67} \mathrm{Ga}$ spectrum.

Figure 2: ${ }^{67}$ Ga citrate radiotracer measurement instrumentation.

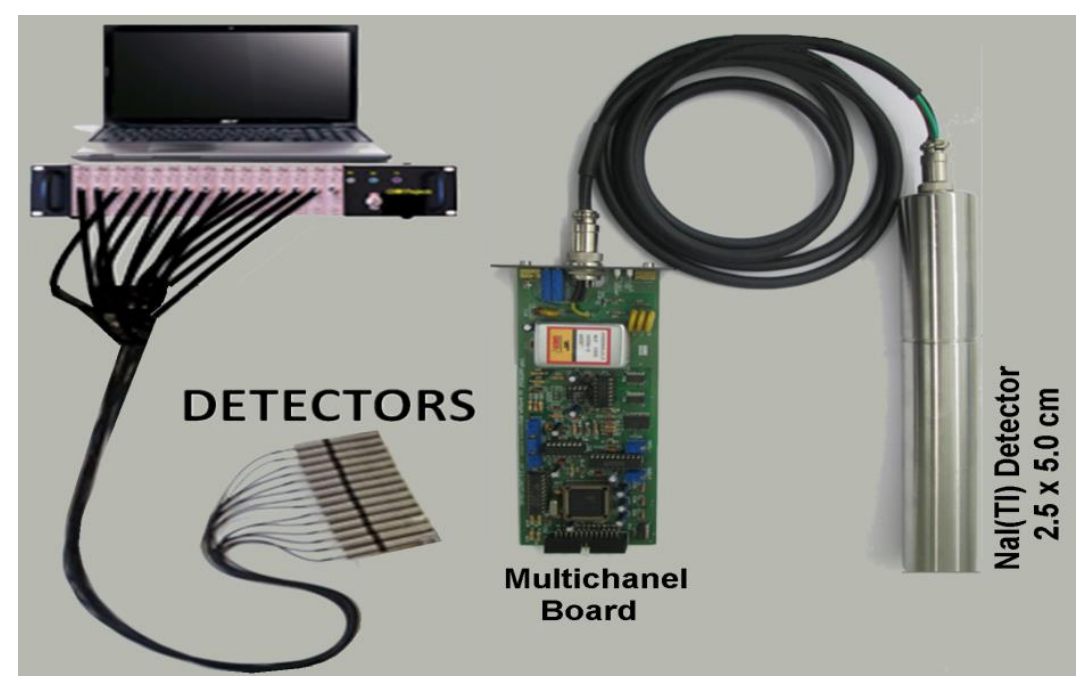




\section{RESULTS AND DISCUSSION}

The kinetics curves for each compartments is shown in Figure 3. Most concentration of the product is present in the chemical reactor (compartment $\mathrm{C}_{1}$ ) until 16 minutes. After that, the reservoir tank keeps most part of the acetone produced. Although a total of seven compartments were used in this analysis, some of them, such as $\mathrm{C}_{5}$ and $\mathrm{C}_{6}$ presented very high values of transfer constants (Table 1), suggesting that they are merely tubular passages, without importance in the context of the kinetics of acetone production. Also, the same conclusions can be inferred from the half-life and residence time parameters (Table 1), which are extremely low for $\mathrm{C}_{5}$ and $\mathrm{C}_{6}$.

Figure 3: ${ }^{67}$ Ga-citrate tracer concentration at different sampling region as showed in Fig. 1 .

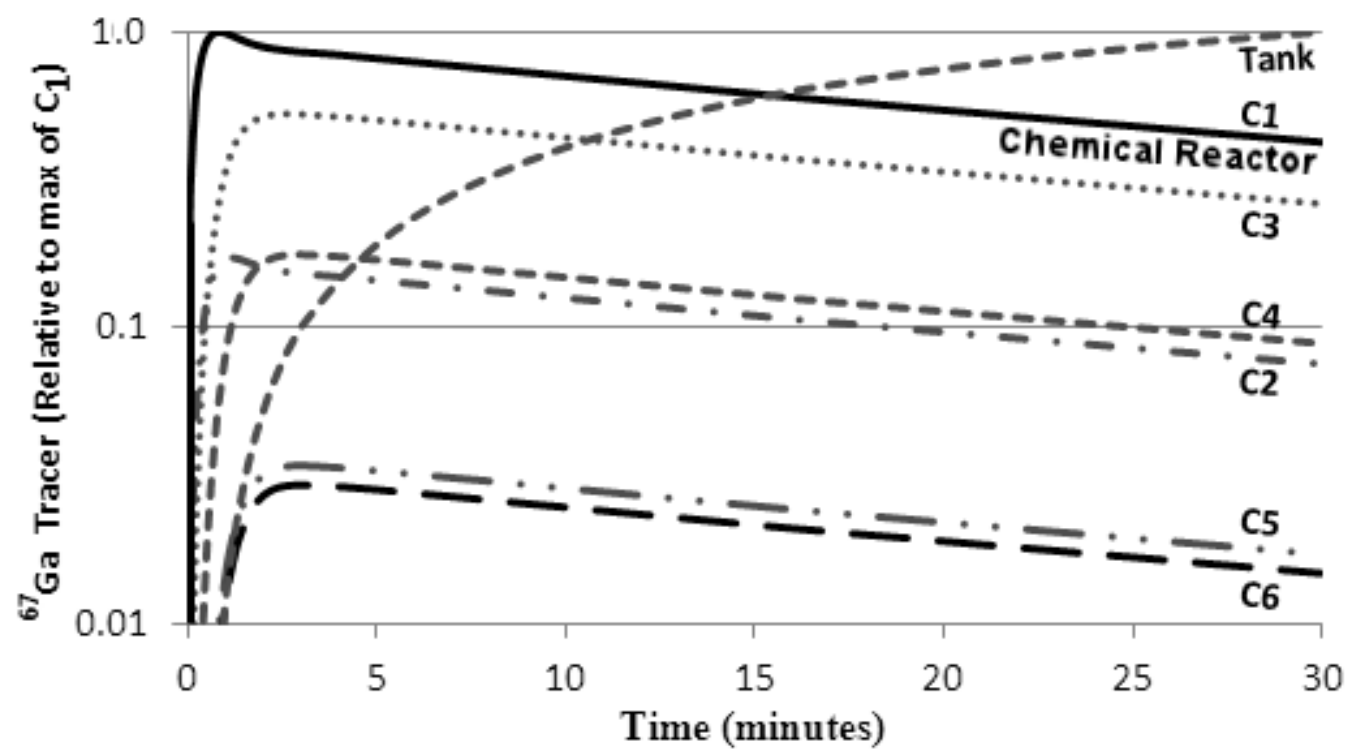

In the present study it was necessary to introduce a relatively unusual artifice in Compartmental Analysis. In conventional procedure, it is usual to set the initial value of the compartment by a constant value. However, in the present study the radioactive tracer was added using a syringe and the tracer ran a relatively long distance between the injection site and the chemical reactor (Fig. 1). Therefore, the radiotracer enters in the compartment $C_{1}$ with profile of a Gaussian curve defined by the function (3). Table 2 shows the time of tracer arrival in each compartment. 


$$
\text { Input to } C_{1}(t)=A \cdot e^{-\frac{(\tau-t)^{2}}{2 \cdot \omega^{2}}}
$$

where, $\tau$ and $\omega$ are presented in Table 3 and $t$ is the respective time elapsed.

Table 1: Numerical results to the kinetic parameters for the model of Fig. 1 .

\begin{tabular}{|c|c|c|}
\hline Parameter & Value & $\pm \mathrm{sd}$ \\
\hline$k_{1,2}\left(\min ^{-1}\right)$ & 8.61 & \pm 1.601 \\
\hline$k_{2,3}\left(\min ^{-1}\right)$ & 48.6 & \pm 0.101 \\
\hline$k_{3,4}\left(\min ^{-1}\right)$ & 13.4 & \pm 4.2 \\
\hline$k_{3,7}\left(\min ^{-1}\right)$ & 0.837 & \pm 2.00 \\
\hline$k_{4,5}\left(\min ^{-1}\right)$ & 39.8 & \pm 23.58 \\
\hline$k_{5,6}\left(\min ^{-1}\right)$ & 206 & \pm 18 \\
\hline$k_{6,1}\left(\min ^{-1}\right)$ & 239 & \pm 4 \\
\hline$k_{7, \operatorname{Tank}}\left(\min ^{-1}\right)$ & 16.8 & \pm 0.8 \\
\hline$T_{1 / 2}^{\mathrm{C} 1}(\min )$ & 0.0805 & \pm 0.0278 \\
\hline$T_{1 / 2}^{\mathrm{C} 2}(\min )$ & 0.0143 & $\pm 9.51 \mathrm{E}-05$ \\
\hline$T_{1 / 2}^{\mathrm{C} 3}(\min )$ & 0.0488 & \pm 0.0325 \\
\hline$T_{1 / 2}^{\mathrm{C} 4}(\min )$ & 0.017 & \pm 0.030 \\
\hline$T_{1 / 2}^{\mathrm{C} 5}(\min )$ & 0.00337 & \pm 0.00216 \\
\hline$T_{1 / 2}^{\mathrm{C} 6}(\min )$ & 0.00290 & \pm 0.000391 \\
\hline$T_{1 / 2}^{\mathrm{C} 7}(\min )$ & 0.0413 & \pm 0.00414 \\
\hline$T_{\text {Residence }}^{C 1}(\min )$ & 0.116 & \pm 0.040 \\
\hline$T_{\text {Residence }}^{C 2}$ (min) & 0.0206 & \pm 0.0001 \\
\hline$T_{\text {Residence }}^{C 3}(\mathrm{~min})$ & 0.0705 & \pm 0.0622 \\
\hline$T_{\text {Residence }}^{C 4}(\min )$ & 0.0251 & \pm 0.0436 \\
\hline$T_{\text {Residence }}^{C 5}(\mathrm{~min})$ & 0.00486 & \pm 0.00312 \\
\hline$T_{\text {Residence }}^{C 6}(\min )$ & 0.00418 & \pm 0.00056 \\
\hline$T_{\text {Residence }}^{C 7}(\mathrm{~min})$ & 0.0595 & \pm 0.0060 \\
\hline
\end{tabular}


Table 2: Time of tracer arrival in each compartmental region.

\begin{tabular}{cc}
\hline $\begin{array}{c}\text { Compartment } \\
\text { (Fig. 1) }\end{array}$ & $\begin{array}{c}\text { Trace Arrival Time } \\
\text { (minutes) }\end{array}$ \\
\hline \hline $\mathrm{C}_{1}$ & 0.8 \\
$\mathrm{C}_{2}$ & 1.1 \\
$\mathrm{C}_{3}$ & 2.6 \\
$\mathrm{C}_{4}$ & 2.9 \\
$\mathrm{C}_{5}$ & 3.0 \\
$\mathrm{C}_{6}$ & 3.0 \\
$\mathrm{C}_{7}$ & 3.0 \\
\hline
\end{tabular}

Table 3: ${ }^{67}$ Ga-citrate input profile in the chemical reactor $\left(C_{1}\right)$ fitted by equation (3).

\begin{tabular}{|c|c|c|}
\hline $\begin{array}{l}\text { Parameters of } \\
\text { Equation (3) }\end{array}$ & Value & \pm SD \\
\hline$\overline{\mathrm{A}}$ & 31375 & \pm 1647 \\
\hline$\tau$ & 0.1707 & \pm 0.00221 \\
\hline$\omega$ & 0.03689 & \pm 0.00228 \\
\hline
\end{tabular}

Table 4 shows the values of the areas under the curves of the tracer content in the compartments $\mathrm{C}_{1}$ and holding tank. The yield of the acetone production was estimated by the percentage ratio between the areas under the curve (AUC) of the profiles of the integral of $\left(\mathrm{C}_{7} / \mathrm{C}_{1}\right)$ resulting a value of $87 \%$ during the first 30 minutes of reaction. 
Table 4: Area under the curve (AUC of $\left.C_{n}=\int_{0}^{t} C_{N} d t\right)$ of the kinetic profile of compartments $C_{1}$ and the reservoir tank $C_{7}$. In the integral the value of $t$ was assumed as $t=30$ minutes to calculate AUC.

\begin{tabular}{lc}
\hline Compartment & AUC \\
\hline $\mathbf{C}_{1}$ (Chemical reactor) & 621 \\
\hline $\boldsymbol{C}_{7}($ Tank) & 539 \\
\hline $\begin{array}{l}\text { Yield of the acetone production } \\
\left(\text { Reaction Yield }=\frac{C_{7} A U C}{C_{1} A U C} \times 100\right)\end{array}$ & $87 \%$ \\
\hline
\end{tabular}

The chemical reaction yield of $87 \%$ is similar to the value described by Gonçalves and Minguita $[8]$.

\section{CONCLUSIONS}

The compartmental analysis theory was useful to evaluate several parameters of the acetone chemical production. Most concentration of the product is present in the chemical reactor (compartment $\mathrm{C} 1$ ) until 16 minutes. After that, the reservoir tank keeps most part of the acetone produced. Although a total of seven compartments were used in this analysis, some of them, such as C5 and C6 presented very high values of transfer constants of $\mathrm{k} 4,5$ and $\mathrm{k} 5,6$, suggesting that they are merely a tubular passages, without importance in context of the kinetics of acetone production. It was possible to obtain several kinetic informations from the chemical process, such as: half-life time, mean-time, residencetime, the yield of the chemical reaction was estimated as $87 \%$ at 30 minutes of substrate reactions using a safe and non-invasive methodology.

\section{ACKNOWLEDGMENT}

The authors would like to express their gratitudes to CNPq (The Brazilian National Research Council) and FAPESP (Foundation for Research Support of the State of São Paulo) for financial support, grants and fellowships. 


\section{REFERENCES}

[1] WITICOFF, H.A., REUBEN, B.G., PLOTKIN, J.S. Industrial Organic Chemicals. 3.ed. Hoboken, NJ: John Wiley \& Sons, Inc., 848p., 2012 (ISBN 978-0-470-53743-5).

[2] ZAKOSHANSKY, V. M. The cumene process for phenol-acetone production. Petroleum Chemistry. vol. 47(4), p. 273-284, 2007.

[3] ICIS. Acetone Production and Manufacturing Process. Houston:ICIS, 2007. Available in: https://www.icis.com/resources/news/2007/11/01/9074860/acetone-production-andmanufacturing-process/. Accessed on October 4, 2017.

[4] FORTUIN, J. P., WATERMAN, H. I. Production of phenol from cumene. Chemical Engineering Science, vol. 3, p.182-192, 1958.

[5] OTHMAN, N. \& KAMARUDIN, S. K. Radiotracer Technology in Mixing Processes for Industrial Application, The Scientific World Journal, vol. 2014, Article ID 768604, 15 pages, 2014.

[6] MARCHESE, S.R.M., MESQUITA, C.H., CUNHA, I.I.L. AnaComp program application to calculate ${ }^{137} \mathrm{C}$ transfer rates in marine organisms and dose in man. $\mathrm{J}$ Radioanal Nucl Chem, vol. 232, p. 233-236, 1998.

[7] Mesquita, C.H., Velo, A.F., Carvalho, D.V.S., Martins, J.F.T., Hamada, M.M. Industrial tomography using three different gamma ray. Flow Measurement and Instrumentation, vol. 47 p. 1-9, 2016.

[8] GONÇALVES, C.C.R. \& MINGUITA, H.F. Estudo de uma planta industrial de produção de acetona via desidrogenação do 2-propanol. Depto. de Engenharia Química. Universidade Federal Fluminense, 2017. Niterói, RJ. 111 f. 